\section{Conflicting information from TGA versus FDA may undermine compliance with use of medication}

To THE EDITOR: Conflicting information about treatments is known to undermine compliance with the use of medications. ${ }^{1}$ The education of patients and caregivers that accompanies prescribing should therefore be as consistent as possible. Clients may conduct research on the internet into particular medicines and try to corroborate "what the doctor said". In the case of the use of clonidine in children, publicly available information is conflicting. The websites of two regulatory agencies, the Therapeutic Goods Administration (TGA) in Australia and the Food and Drug

Administration (FDA) in the United States, give conflicting information on using this $\alpha-2$ adrenergic agonist. Doctors in Australia may refer patients to the TGA website for information on clonidine, but in doing so will only provide information on the use of clonidine for hypertension. However, paediatricians and child and adolescent psychiatrists may use clonidine (following guidance used in other countries) in children and adolescents for diverse beneficial effects in managing attention deficit- hyperactivity disorder (ADHD), outside its TGA-approved use. ${ }^{2}$

The TGA's consumer medical information $(\mathrm{CMI})^{3}$ and product information (PI $)^{4}$ for clonidine state:

Catapres is not recommended for use in children and teenagers up to 18 years of age. Serious side effects have been observed when clonidine, the active ingredient in Catapres, is used with methylphenidate in children with ADHD. Therefore, Catapres in this combination is not recommended. ${ }^{3}$

The use and the safety of clonidine in children and adolescents has little supporting evidence.... and therefore can not be recommended for use in this population. ${ }^{4}$

Read et al

The Pharmaceutical Benefits

Scheme website has hyperlinks to both PI and CMI on the website of the TGA.

A problem arises if a client seeks information about prescribed medication from other jurisdictions such as the US. In their statistical review and evaluation of clonidine, the FDA states, based on most recent evidence, that:

CLONICEL [the trade name for clonidine in the US] is efficacious, as a monotherapy and as an addon to a psychostimulant, in the treatment of subjects (6-17 yearsold) with ADHD. ${ }^{5}$

Therefore compliance with medication regimens may be undermined by conflicting information from the TGA and FDA. Clinicians need to be aware of the 
differences in information and recommendations disseminated by authoritative sources and be prepared when they counsel patients. Perhaps the TGA should review its CMI and PI to reflect recent evidence that clonidine, with the necessary cautions, can be safely prescribed to some selected children and adolescents.

\section{Klaus Martin Beckmann Psychiatrist}

Evolve Therapeutic Services, Queensland Health, Brisbane, QLD.

martinbeckmannnn@hotmail.com

Competing interests: No relevant disclosures. doi: 10.5694/mjal3.10086

1 Mitchell AJ, Selmes T. Why don't patients take their medicine? Reasons and solutions in psychiatry. APT 2007; 13: 336-346.

2 Waknine Y. FDA approves extended-release clonidine for pediatric ADHD. Medscape Medical News 2010; 7 Oct. http://www.medscape.com/ viewarticle/730140 (accessed Apr 2013).

3 Therapeutic Goods Administration. Catapres 100 Tablets. Clonidine hydrochloride. Consumer medication information (CMI). Canberra: TGA, 2010. https://www.ebs.tga.gov.au/ebs/picmi/ picmirepository.nsf/pdf?OpenAgent\&id=CP2010-CMl-02397-3 (accessed Apr 2013).

4 Therapeutic Goods Administration. Catapres 100 tablets. Product information. Canberra: TGA, 2013. https://www.ebs.tga.gov.au/ebs/picmi/ picmirepository.nsf/pdf?OpenAgent\&id=CP2010-PI-02401-3 (accessed May 2013).

5 United States Department of Health and Human Services, Food and Drug Administration, Center for Drug Evaluation and Research, Office of Translational Sciences, Office of Biostatistics. Statistical review and evaluation: clinical studies. NDA/Serial Number 22331. Clonidine (clonidine $\mathrm{HCl}$ modified release). http://www.fda.gov/ downloads/drugs/developmentapprovalprocess/ developmentresources/ucm265920.pdf (accessed Apr 2013). 